\title{
8
}
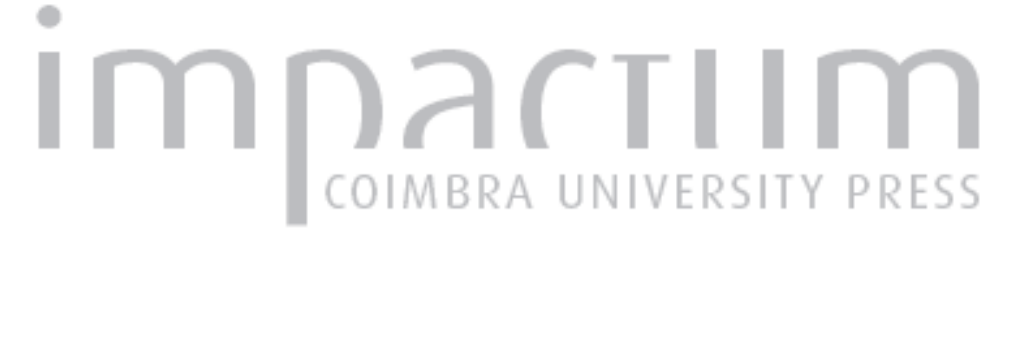

\section{Mapeamento do uso do solo da bacia Ribeirão Engenho de Ferro - Ibiporã - PR - Brazil, entre 1990 e 2010}

\author{
Autor(es): $\quad$ Silva, Elaine Elise Lapa da; Pereira Neto, Osvaldo Coelho; Cainzos, \\ Rigoberto Lazaro Prieto; Stipp, Nilza Aparecida Freres \\ Publicado por: Associação Portuguesa de Riscos, Prevenção e Segurança \\ URL \\ persistente: \\ URI:http://hdl.handle.net/10316.2/35848 \\ DOI: \\ DOI:http://dx.doi.org/10.14195/1647-7723_20_15 \\ Accessed : $\quad$ 26-Apr-2023 15:32:47
}

A navegação consulta e descarregamento dos títulos inseridos nas Bibliotecas Digitais UC Digitalis, UC Pombalina e UC Impactum, pressupõem a aceitação plena e sem reservas dos Termos e Condições de Uso destas Bibliotecas Digitais, disponíveis em https://digitalis.uc.pt/pt-pt/termos.

Conforme exposto nos referidos Termos e Condições de Uso, o descarregamento de títulos de acesso restrito requer uma licença válida de autorização devendo o utilizador aceder ao(s) documento(s) a partir de um endereço de IP da instituição detentora da supramencionada licença.

Ao utilizador é apenas permitido o descarregamento para uso pessoal, pelo que o emprego do(s) título(s) descarregado(s) para outro fim, designadamente comercial, carece de autorização do respetivo autor ou editor da obra.

Na medida em que todas as obras da UC Digitalis se encontram protegidas pelo Código do Direito de Autor e Direitos Conexos e demais legislação aplicável, toda a cópia, parcial ou total, deste documento, nos casos em que é legalmente admitida, deverá conter ou fazer-se acompanhar por este aviso.

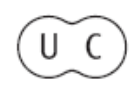




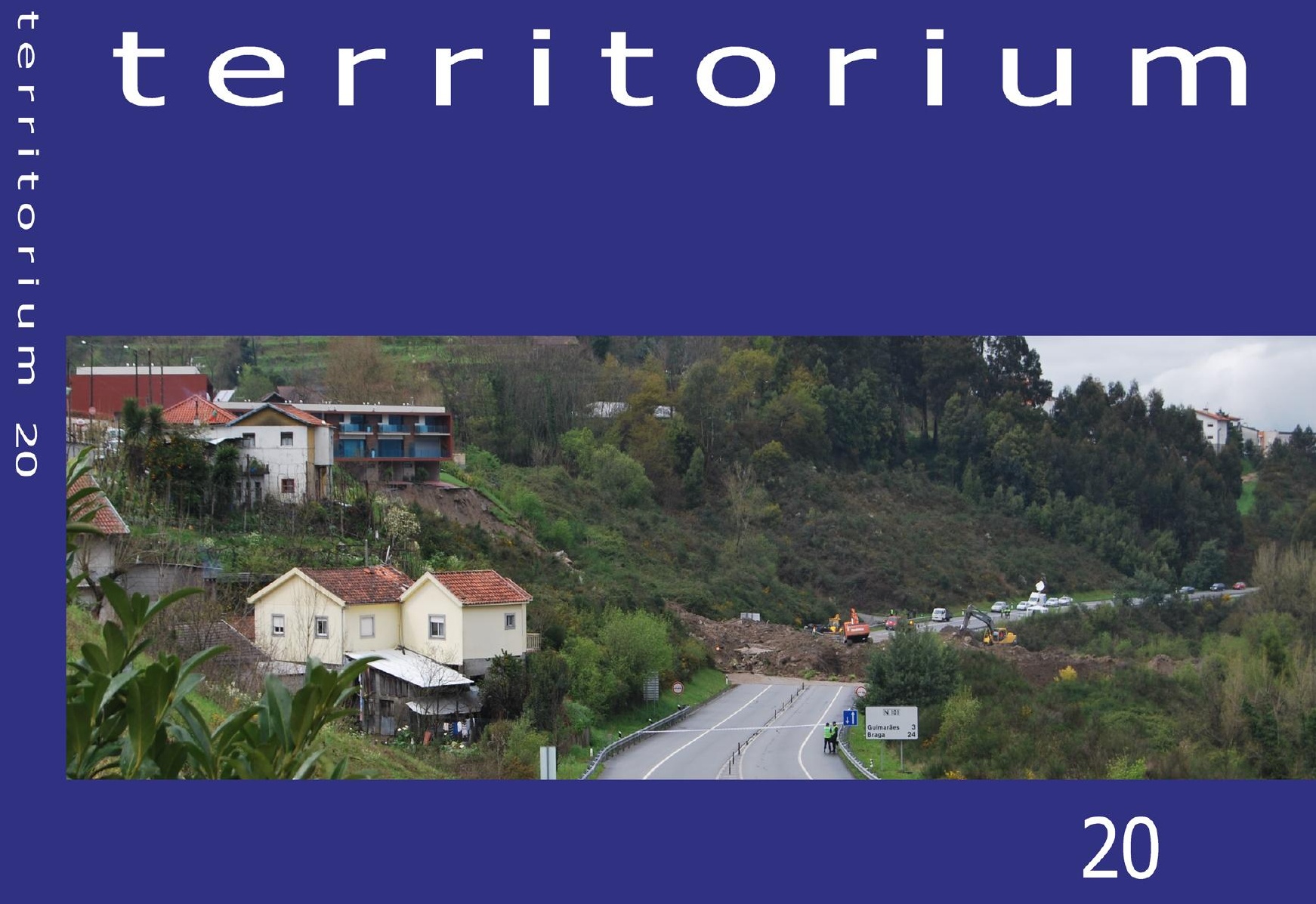

Riscos, População e Segurança 
territorium 20

\section{MAPEAMENTO DO USO DO SOLO DA BACIA RIBEIRÃO ENGENHO DE FERRO - IBIPORÃ - PR - BRAZIL, ENTRE 1990 E 2010*}

Elaine Elise Lapa da Silva

Departamento de Geociências, Centro de Ciências Exatas (CCE), da Universidade Estadual de Londrina (UEL) elainelapa@hotmail.com

Osvaldo Coelho Pereira Neto

Departamento de Geociências, Centro de Ciências Exatas (CCE), da Universidade Estadual de Londrina (UEL) coelho@uel.br

Rigoberto Lazaro Prieto Cainzos

Departamento de Geociências, Centro de Ciências Exatas (CCE), da Universidade Estadual de Londrina (UEL) rigoberto@uel.br

Nilza Aparecida Freres Stipp

Departamento de Geociências, Centro de Ciências Exatas (CCE), da Universidade Estadual de Londrina (UEL) nfreres@sercomtel.com.br

\section{Introdução}

Os avanços tecnológicos na área espacial trazem melhorias significativas na resolução espacial, radiométrica, espectral e temporal dos dados orbitais. Os satélites são capazes de diferenciar alvos na superfície terrestre, principalmente devido à melhoria na resolução espacial.

Adisponibilidade de informações seguras sobre a dinâmica do uso do solo é muito importante para os vários setores envolvidos em estudos ambientais, e uma alternativa viável para o fornecimento dessas informações é o uso das técnicas de sensoriamento remoto, que permitem analisar imagens da superfície terrestre adquirida por meio de sensores de satélites.

A partir do uso de imagens de satélites e técnicas de geoprocessamento, será realizada uma análise das mudanças no uso do solo da Bacia Ribeirão Engenho de Ferro, localizada no município de Ibiporã - PR - Brasil, nos anos de 1990, 2000 e 2010. Espera-se que a análise de imagens de satélites identifique as mudanças no uso do solo ao longo do tempo.

0 trabalho pode servir de base para futuros planejamentos ambientais, no tocante a previsões de áreas de risco, e também como um subsídio importante para o planejamento de regiões semelhantes à do estudo em questão.

\section{Revisão Bibliográfica}

Levantamentos sobre recursos naturais e uso da terra são de extrema importância como auxílio ao planejamento, monitoramento e controle do processo de ocupação do solo e seus riscos inerentes. Neste contexto, tornam-se necessários estudos com o objetivo de caracterizar e monitorar o meio físico, e que dêem suporte a execução de ações voltadas à recuperação dessas áreas.
Uma ferramenta que tem se mostrado eficaz para pesquisas dessa natureza é sensoriamento remoto orbital, já que possibilita em um curto espaço de tempo a obtenção de uma grande quantidade de informações. Aliado ao geoprocessamento, o sensoriamento remoto constitui-se numa tecnologia indispensável ao estudo e a análise das variações ambientais terrestres e seus riscos.

As atividades do geoprocessamento são efetuadas por sistemas comumente conhecidos como Sistemas de Informação Geográfica (SIG), ou Geographic Information System - GIS. Eles processam dados gráficos e não gráficos com ênfase em análises espaciais e modelagens de superfícies; é um conjunto de ferramentas para coletar, armazenar, recuperar, transformar e apresentar dados espaciais oriundos do mundo real para um conjunto de objetivos específicos (Peter A. Burrough e Rachael A. McdonnelL, 1998).

O sensoriamento remoto pode ser definido, de acordo com Philip N. SLATER (1980), como a coleta de informações sobre os recursos naturais da Terra a partir de sensores em aeronaves ou satélites.

O acompanhamento e avaliação dos impactos do uso do solo sobre os ambientes naturais através de imagens de satélites são fundamentais para que se faça o planejamento ideal de áreas de risco.

Além disso, sabe-se que a crescente urbanização e o acelerado crescimento populacional, acompanhado pelo desenvolvimento cada vez maior de modernas técnicas agrícolas, levam ao uso acentuado do solo, seja para a agricultura ou também para uso urbano.

O termo "uso do solo" é baseado na dimensão funcional do solo para diferentes objetivos ou atividades econômicas, como o uso industrial, transporte, recreação ou área de proteção à natureza. Esse uso pode provocar alguns danos ao meio ambiente, como erosão intensa,

* Esta nota é parte integrante da Revista Territorium, n. ${ }^{\circ} 20,2013,{ }^{\circ}$ Riscos, ISBN: 0872- 8941, tendo sido submetida para revisão em 28-06-2012, e aceite para publicação em 12-11-2012. 
inundações, assoreamento dos reservatórios e cursos d’água (OECD, 2005).

Segundo Peter A. Burrough e Rachael A. McdonnelL (1998), o geoprocessamento constitui uma técnica fundamental para a manutenção de registros do uso da terra ao longo do tempo. As imagens de satélite são muito importantes e úteis, pois permitem avaliar as mudanças ocorridas na paisagem de uma região em um dado período, registrando a cobertura vegetal em cada momento.

Verifica-se, então, que a identificação e mapeamento do uso dos solos servem como auxílio para planejamentos, levantamentos, estudos e monitoramentos ambientais de áreas de risco. Há diversos trabalhos realizados baseados nas imagens coletadas pelo satélite Landsat 5 .

Cíntia H. Vasconcelos e Evlyn M. Leão de Moraes Novo (2004) realizaram um mapeamento do uso e cobertura da terra para o ano de 1996 e 2001 a partir da segmentação e classificação de imagens. A área de estudo engloba os municípios de Tucuruí, Jacundá e Novo Repartimento - PA - Brasil. No estudo foram utilizadas imagens Landsat5-TM, e os dados foram processados no software SPRING 3.6. Em Jacundá a área ocupada por atividades agrossilvopastoris em 2001 foi quase duas vezes maior que a área ocupada em 1996. Pode-se observar também que grande parte das áreas que estavam em processo de regeneração em 1996 (mais de 45\%), passou a ser ocupada por atividades agrossilvopastoris em 2001. Esse panorama aumenta intensamente a probabilidade da ocorrência de riscos de erosão do solo da região.

Marcelo de O. Latuf, Mauro A. Martinez e Fernando Pruskl (2007) mapearam o uso do solo no entorno da bacia do Rio Preto - MG - Brasil, no período compreendido entre 1985 e 2000. Após a aquisição das imagens do satélite Landsat5 qualificaram as imagens no software Spring 4.2, a fim de identificar com exatidão as amostras, classificando as classes de uso em: floresta, cerrado, reservatórios, pastagem, cultivos e urbanização. A utilização das imagens, de acordo com os resultados, foi satisfatória, pois contemplou com exatidão o monitoramento do uso do solo na bacia em estudo. Observou-se um aumento das áreas de cultivos e diminuição da classe do cerrado.

\section{Material e metodologia}

A área estudada foi a Bacia Hidrográfica Ribeirão Engenho de Ferro, localizada no município de Ibiporã, no estado do Paraná, Brasil (Fig. 1), entre as latitudes de $23^{\circ} 15^{\prime} 28^{\prime \prime} S$ e $23^{\circ} 19^{\prime} 25^{\prime \prime} S$ e as longitudes de $50^{\circ} 58^{\prime} 25^{\prime \prime} \mathrm{W}$ e $51^{\circ} 05^{\prime} 22^{\prime \prime}$, estando a uma altitude de 487 metros. $\mathrm{Na}$ fig. 2, pode-se ver a exata localização da bacia.

Foram utilizadas técnicas de geoprocessamento com imagens orbitais do satélite Landsat e com o software SPRING (Gilberto CAMARA et al., 1996), já que estes

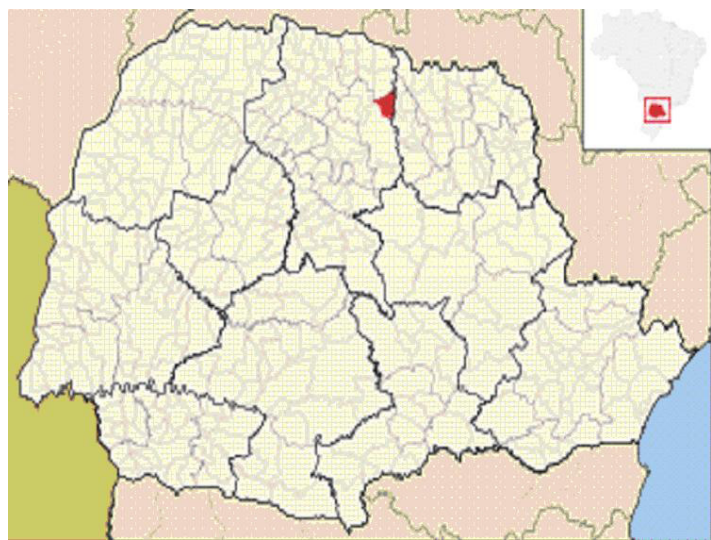

Fig. 1 - Localização do município de Ibiporã - PR - Brasil. Fonte: WIKIPEDIA FOUNDATION, 2006.

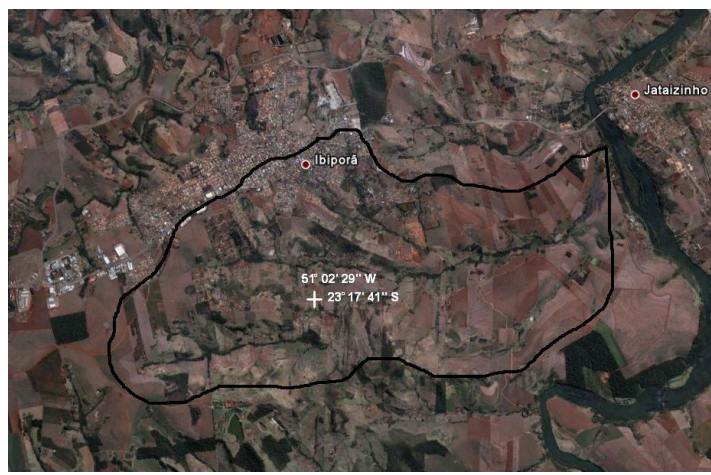

Fig. 2 - Localização da Bacia Ribeirão Engenho de Ferro. Fonte: GOOGLE EARTH, 2012.

representam uma importante ferramenta para a análise ambiental, que no caso específico deste trabalho podem diagnosticar as características de mudanças de uso do solo ao longo do tempo e possíveis áreas de risco.

Segundo a NASA (National Aeronautics and Space Administration), o Programa Landsat é uma série de missões de observação da Terra por satélite gerido pela própria administração, e teve início em 1972 nos Estados Unidos. 0 objetivo principal do sistema Landsat foi o mapeamento multispectral da superfície da Terra, possuindo uma órbita polar heliossíncrona com altitude nominal de $705 \mathrm{~km}$, resolução espacial de 30 metros e inclinação orbital de $98^{\circ}$, completando o ciclo de imageamento da Terra a cada 16 dias. Atualmente o único satélite em operação é o LANDSAT-5, que leva a bordo o sensor TM (Thematic Mapper) e contribui para o mapeamento temático da superfície terrestre.

O software "SPRING" foi desenvolvido pelo INPE (Instituto Nacional de Pesquisas Espaciais), pela EMBRAPA (Empresa Brasileira de Pesquisas Agropecuárias) e pela IBM (International Business Machine). É um sistema de informação geográfico, que inclui um banco de dados geográficos, o qual permite adquirir, armazenar, combinar, analisar e recuperar informações codificadas espacial e não espacialmente, ou seja, é um sistema que combina funções de processamento de imagens, análise 
espacial e modelagem numérica do terreno, em um único software (INPE, 2009).

As imagens de satélite foram adquiridas no site do INPE (www.inpe.br) através de download das bandas espectrais 3, 4 e 5 abrangendo o município de lbiporã nas datas 22/08/1990, 23/12/200 e 01/11/2010, coordenada órbita/ponto $222 / 76$.

Todas as imagens obtidas foram importadas para o software "SPRING", estando todas já georreferenciadas. Foi feito o aumento de contraste linear em todas as bandas para melhorar a discriminação visual dos diferentes elementos da paisagem analisada. Foi selecionada a composição colorida RGB 543.

Foi traçado o limite aproximado da bacia hidrográfica com base na visualização da rede de drenagem e usou-se esse limite para recortar a área de estudo, individualizando-a do restante da imagem. Com isso, o tamanho da mesma fica menor, aumentando a rapidez do processamento e diminuindo o espaço para armazenamento.

Após isso, passou-se à fase de classificação digital supervisionada por região. Foi feita a segmentação das imagens, sendo " 35 " o valor da similaridade e "4" o valor da área. A classificação foi feita com o classificador Bhattacharya, com índice de aceitação 99,9\%.

$\mathrm{Na}$ fase final, as imagens classificadas foram transformadas em imagens temáticas e calculado a área de cada uma das classes de uso do solo que foram mapeadas (mata, solo nu, pasto, cultura e urbano).

\section{Resultados e discussões}

As figuras 3, 4 e 5 apresentam os mapas de uso do solo para os anos de 1990, 2000 e 2010, respectivamente, e a TABELA I mostra a quantificação das áreas das classes de uso do solo dos mesmos anos.

O desempenho das amostras obtido da classificação digital Bhattacharya, que foram de 100\% para 1990, $97,97 \%$ para 2000 e de $99,40 \%$ para 2010 , demonstra, pelos altos valores, que houve critério e precisão na escolha das amostras para a classificação digital.

TABELA I - Cálculo das áreas de uso do solo no período estudado $\left(\mathrm{em} \mathrm{km}{ }^{2}\right)$.

\begin{tabular}{|c|c|c|c|}
\hline Classes & $\begin{array}{c}\text { Ano } \\
1990\end{array}$ & $\begin{array}{c}\text { Ano } \\
2000\end{array}$ & $\begin{array}{c}\text { Ano } \\
2010\end{array}$ \\
\hline Mata & 3.5091 & 2.5155 & 4.4757 \\
\hline Cultura & 18.5220 & 24.6710 & 14.9040 \\
\hline Pasto & 8.7030 & 6.1164 & 9.1080 \\
\hline Solo nu & 3.1896 & 1.7559 & 5.4018 \\
\hline Área urbana & 3.7980 & 2.6757 & 3.8124 \\
\hline Total & 37.7220 & 37.7350 & 37.7020 \\
\hline
\end{tabular}

A bacia hidrográfica Ribeirão Engenho de Ferro apresentou significativas alterações no uso do solo em relação aos anos estudados.

No ano de 1990, a cobertura da bacia em relação à mata era de $3,50 \mathrm{~km}^{2}$; em 2000, registrou-se uma cobertura de $2,51 \mathrm{~km}^{2}$, verificando-se que, em dez anos, houve uma perda de $0,99 \mathrm{~km}^{2}$ de área de mata. De 2000 a 2010 ocorreu um ganho de $1,96 \mathrm{~km}^{2}$ de mata, registrando-se, em vinte anos, um aumento da área da mata em 0,96 $\mathrm{km}^{2}$, apesar da perda que houve no ano de 2000. Isso pode ser reflexo das políticas ambientais proibitivas com relação ao desmatamento, mostrando uma resposta positiva de aumento das áreas de mata no período, diminuindo a probabilidade de ocorrências de riscos erosivos nos córregos.

Em relação à cultura, no ano de 1990 registrou-se uma cobertura de $18,52 \mathrm{~km}^{2}$, com um aumento para 24,67 $\mathrm{km}^{2}$ no ano de 2000; logo, em dez anos a área de cultura cresceu $6,15 \mathrm{~km}^{2}$. No entanto, em 2010, houve uma diminuição das áreas de cultura para $14,90 \mathrm{~km}^{2}$. Deste modo, entre os anos de 2000 e 2010 a área de cultura foi reduzida em $9,77 \mathrm{~km}^{2}$, havendo uma diminuição da cultura de 3,62 km² em relação aos anos de 1990 a 2010. A bacia estudada mostra aqui sua tendência para agricultura, perfazendo, nos 3 anos estudados, a maior parte da área mapeada. Essas áreas podem apresentar riscos erosivos se caso não forem implantadas técnicas de conservação e manejo de solo.

Quanto ao pasto, em 1990, a área era de $8,70 \mathrm{~km}^{2}$, notando-se uma queda para $6,11 \mathrm{~km}^{2}$, representando uma perda de 2,59 km² no ano de 2000. Em 2010 a perda foi recuperada e ainda houve um aumento de $0,40 \mathrm{~km}^{2}$ em relação ao ano de 1990. O pasto foi a segunda maior área mapeada nos 3 anos estudados, oscilando pouco no período e concentrando-se ao sul da porção central da bacia, onde se localizam as áreas de maior declividade. Essas áreas, por estarem em locais mais declivosos, também exigem manejo conservacionista adequado para evitar riscos ambientais.

Verificou-se que no ano de 1990, a área de solo nu era de $3,18 \mathrm{~km}^{2}$, diminuindo, em dez anos, para $1,75 \mathrm{~km}^{2}$. No entanto, de 2000 a 2010 averiguou-se uma ampliação de $3,64 \mathrm{~km}^{2}$ da área de solo nu. Essas áreas provavelmente são áreas que correspondem à agricultura, confirmando ainda mais a tendência agrícola da bacia.

A área urbana, em relação ao total da bacia, apresenta uma pequena extensão, uma vez que existe grande área de cultura e de pasto. No ano de 1990, a área apresentava uma extensão de $3,79 \mathrm{~km}^{2}$, havendo uma diminuição para 2,67 km² dez anos após. Na verdade, essa queda na extensão de área urbana não é real; isso se deve à limitação que ocorre no uso da classificação digital, onde o algoritmo baseia-se na semelhança entre os pixels 
para fazer o mapeamento. Isso pode acarretar erro de classificação, pois a área urbana é a feição da paisagem que mais apresenta mescla de cores, interferindo muito na tomada de decisão do algoritmo de classificação. A área aumenta nos dez anos seguintes para $3,81 \mathrm{~km}^{2}$, significando um pequeno acréscimo de $0,02 \mathrm{~km}^{2}$ em vinte anos, mostrando que a cidade de Ibiporã praticamente manteve-se inalterada no seu crescimento urbano.

Quanto à área total da bacia hidrográfica Ribeirão Engenho de Ferro, identificou-se uma pequena mudança no total calculado em relação aos anos 1990, 2000 e 2010, que foram de $37,72 \mathrm{~km}^{2}, 37,73 \mathrm{~km}^{2}$ e $37,70 \mathrm{~km}^{2}$, respectivamente. Essa ligeira oscilação é uma limitação

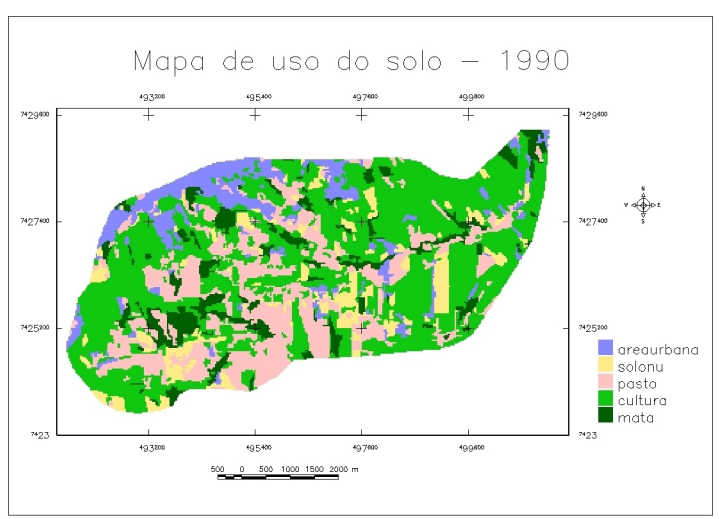

Fig. 3 - Mapa de uso do solo no ano de 1990.

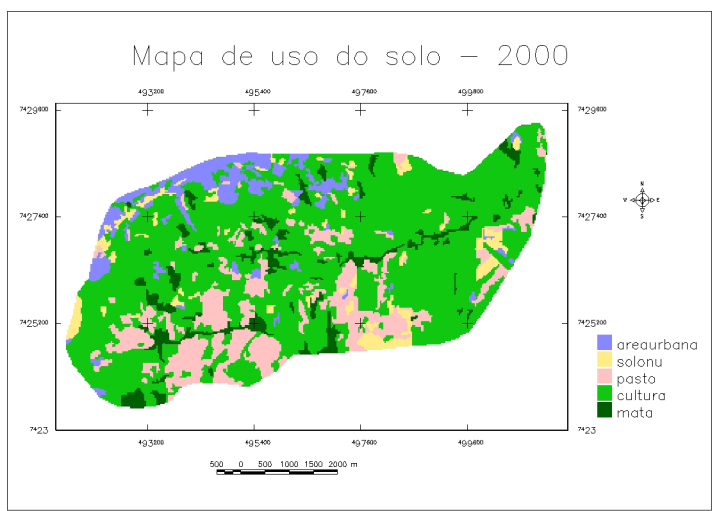

Fig. 4 - Mapa de uso do solo no ano de 2000.

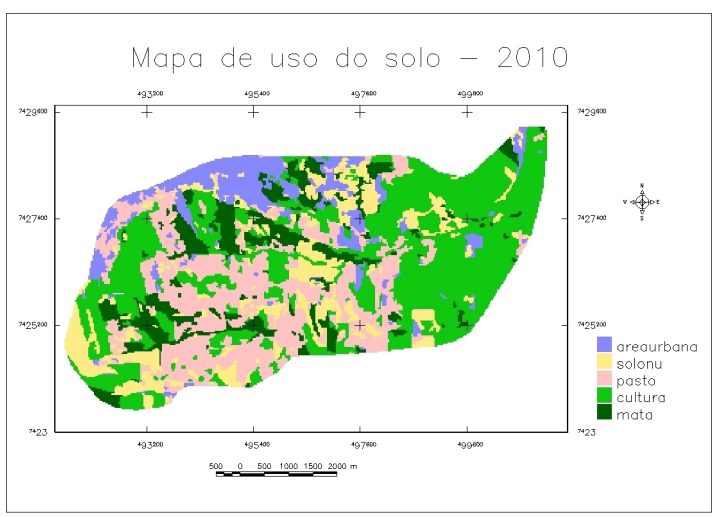

Fig. 5 - Mapa de uso do solo no ano de 2010. inerente ao sistema, uma vez que ele se baseia nos pixels da imagem, que são quadrados, para mapear a bacia. Isso gera uma aproximação diferente para cada mapeamento ao quantificar a área próxima ao limite da bacia, pois as linhas que fazem o limite da bacia são inclinadas; assim, os quadrados dos pixels são quantificados seguindo as linhas inclinadas do limite vetorial da bacia, resultando em alguma diferença de extensão de área.

\section{Conclusão}

As imagens de satélite, assim como o software utilizado, permitiram atingir os objetivos propostos, ou seja, a elaboração do mapa de uso do solo do município de Ibiporã e a avaliação da área ocupada nos anos de 1990, 2000 e 2010.

A partir dos dados obtidos de uso e ocupação do solo, verificou-se uma forte tendência agropecuária nouso do solo na bacia, ao longo de todo o período, necessitando de um forte planejamento de conservação e manejo do solo para evitar riscos ambientais, tanto erosivos quanto químicos.

Em relação à mata, de 1990 a 2010, constatou-se um aumento das áreas de mata na bacia. Verifica-se que tal resultado pode ser em virtude de políticas ambientais de proibição do desmatamento, o que diminui o risco de ocorrência de assoreamento de rios com os processos erosivos.

\section{Referências Bibliográficas}

Burrough, Peter A., Mcdonnell, Rachael A. (1998) "Principles of Geographical Information Systems”. Oxford University Press: Oxford.

Camara, Gilberto., Souza, R.C.M., Freitas, U.M., Garrido, J. SPRING (1996) - Integrating remote sensingand GIS by object-oriented data modelling. “Computers \& Graphics”, 20: (3) 395-403, May-Jun.

INPE - Instituto Nacional de Pesquisas Espaciais. Divisão de Sensoriamento Remoto. "Sistema de Processamento de Informações Georreferenciadas". São José dos Campos: São Paulo, 2009. Disponível em: http://www.dpi.inpe.br/ spring/portugues/index.html. Acesso em: 16 abr. 2011.

Latuf, Marcelo de O.; Martinez, Mauro A.; Pruski, Fernando F.; SILVA, Demetrius D., (2007) - Mudanças no uso do solo nas bacias do rio Preto e ribeirão Entre Ribeiros/MG a partir de imagens do sensor Landsat 5 TM. In: "SIMPÓSIO BRASILEIRO DE SENSORIAMENTO REMOTO”, 13 ,2007, Florianópolis. Anais... Florianópolis: UFV, p. 5855-5862. 
NATIONAL AERONAUTICS AND SPACE ADMINISTRATION. "The Landsat Program". USA, 2011. Disponível em: http: / / landsat.gsfc. nasa.gov/. Acesso em: 18 abr. 2011.

OECD - Organisation for Economic Co-operation and Development. "Glossary of statstical terms: Land Use”. Paris, 2005. Disponível em: http:// stats.oecd.org/glossary/detail.asp?ID=6493. Acesso em janeiro 2012.

Slater, Philip N. (1980) - "Remote Sensing: optics and optical systems". Addison-Wesley Publishing: Massachusetts.

VAsconcelos, C. H.; Novo (2004) - E. Mapeamento do uso e cobertura da terra a partir da segmentação e classificação de imagens - fração solo, sombra e vegetação derivadas do modelo linear de mistura aplicado a dados do sensor TM/ Landsat5, na região do reservatório de Tucuruí - PA. In: "ACTA AMAZONICA", São José dos Campos v. 34 (3), p. 487-493. Disponível em: http: / /acta.inpa.gov.br/fasciculos/34-3/PDF/ v34n3a14.pdf. Acesso em: 03 jun. 2011.

WIKIPEDIAFOUNDATION. Ficheiro: Parana Municip Ibipora. 2006. Disponível em: http://pt.wikipedia.org/ wiki/Ficheiro:Parana_Municip_lbipora.svg, Acesso em jan.2012.

\section{ANÁLISE DAS CONDIÇÕES DO AMBIENTE TÉRMICO EM SERVIÇOS HOSPITALARES DE MEDICINA FÍSICA E DE REABILITAÇÃO*}

\section{Rodrigues}

PROA/LABIOMEP/CIGAR, Faculdade de Engenharia da Universidade do Porto pee10017@fe.up.pt

J. Santos Baptista

PROA/LABIOMEP/CIGAR, Faculdade de Engenharia da Universidade do Porto jsbap@fe.up.pt

M. Brito

CMUP, Faculdade de Ciências da Universidade do Porto mabrito@fc.up.pt

\section{Introdução}

Um dos fatores de risco físico dos serviços de medicina física e de reabilitação, de qualquer estabelecimento hospitalar é o ambiente térmico, na medida em que profissionais e doentes partilham o mesmo espaço, sujeitos às mesmas condições térmicas, mas com atividade metabólica diversa. Nesta medida, as consequências para uns e outros, quando expostos, no ginásio de reabilitação, às mesmas condições de ambiente térmico é explicada, em grande medida, pela atividade que cada um desenvolve. No caso dos profissionais destes serviços, a temperatura interna pode aumentar, entre outras razões, devido à atividade física e à adoção de posturas exigentes, as quais poderão conduzir a situações de desconforto térmico. Nos doentes, a capacidade física debilitada, associada ao consumo de medicamentos, vão afetar a função metabólica e a perceção de conforto térmico. Temos assim dois grupos para os quais as mesmas condições ambientais podem resultar em consequências diversas.
Nos profissionais, uma situação de desconforto térmico, pode conduzir à adoção de práticas de trabalho inseguras, pelo que poderá haver um aumento da probabilidade de ocorrência de acidentes que será tanto maior quanto maior for o estado de desconforto. Quanto aos doentes, as consequências do desconforto são diferentes. Pela maior dificuldade em controlarem a temperatura interna do corpo, poderão ter mais dificuldade de recuperação e ver, mesmo, agravado o seu estado clínico.

0 presente estudo tem como objetivo analisar as condições do ambiente térmico de alguns ginásios terapêuticos, do serviço de medicina física e reabilitação, de diferentes unidades hospitalares, com vista a identificar os principais parâmetros de variação de conforto térmico e promover a adoção de medidas de conforto térmico seguras, saudáveis e sustentáveis e que possam abranger o maior número, possível, de pessoas.

* O texto desta nota corresponde à comunicação apresentada ao VII Encontro Nacional de Riscos e I Forum ISCIA, tendo sido submetida para revisão em 28-09-2012, e aceite para publicação em 12-11-2013.

Esta nota é parte integrante da Revista Territorium, n. ${ }^{\circ} 20,2013,{ }^{\circ}$ RIscos, ISBN: 0872- 8941. 